\title{
SOME PROPERTIES OF THE PORE SYSTEM IN BRICKS AND THEIR RELATION TO FROST ACTION
}

\author{
By Ray T. Stull and Paul V. Johnson
}

\begin{abstract}
In the study of certain properties of the pore system in bricks and their relation to frost action, the following determinations were made on seven series of bricks: Percentage of porosity; variation in porosity within a brick; permeability to air and water; the flow of air through two members in series; mean effective capillary radius and the number of capillaries in an ideal structure, which would have the same permeability value as that determined experimentally for the brick; saturation coefficient by 48 hours' immersion; increase in saturation coefficient with repeated freezing and thawing; and resistance of the bricks to failure by repeated freezing and thawing. The data are presented in 14 tables.
\end{abstract}

\section{CONTENTS}

I. Introduction

II. Materials and properties studied

1. Selection of specimens _._.

2. Properties determined

III. Methods and apparatus_._. 713

1. Preparation of the specimens _.

2. Porosity

(a) Definition of porosity

(b) Bulk volume._.

(c) Solid volume........ 714

(d) Porosity of different sections of a brick

3. Permeability _._.

(a) Definition of permeability

(b) Apparatus for determining air permeability ......... 716

(1) Air transmission of two members in series . . 717

(c) Apparatus for determining water permeability ........ 718

4. Determining mean effective radius and number of capillaries ... 719

5. Freezing and thawing tests...... 719

(a) Procedure _........ 719

(b) Saturation coefficient

(c) Increase in saturation coefficient with repeated freezing and thawing

IV. Results and discussion

1. Variation in porosity within a brick

2. Permeability to air and water

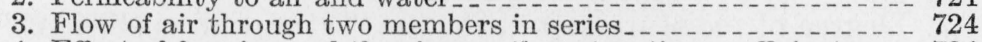

4. Effect of freezing and thawing on the saturation coefficient

5. Relations of porosity, permeability, effective capillary radius, number of capillaries, and saturation coefficient to the number of freezing and thawing cycles causing failure of bricks_..- 725

V. Summary _. 


\section{INTRODUCTION}

In a discussion of pore size and arrangement in sandstone and compacted sand, Slichter ${ }^{1}$ shows that the form and size of the pores depend upon the grain size, shape, and degree of compactness or grain arrangement. For spherical grains of the same size, the maximum pore space results when the grains are arranged in a rectangular pattern and the minimum when the pattern is "triangular." With more or less rounded grains, well-compacted, the pores are in the form of irregular, truncated, tetrahedral voids interconnected at the truncations, or smallest cross sections, so as to form a network of irregularly shaped passages of variable cross section which function in a manner similar to that of a bundle of cylindrical capillary tubes.

The form and arrangement of the pores of kiln-fired clay products are considered similar to those of fine-grained sandstone, where the pores vary in size down to and including those of micro size. When formed from the plastic clay and dried, the internal structure consists of a compacted mass of mineral grains and, during the firing process, the pores change more or less in size, but probably change very little in general form up to some point below the vitrified condition.

The pore arrangement pictured by Slichter is essentially rectilinear and does not seem quite appropriate to the arrangement in bricks. For, when considered en masse, the arrangement appears more probably to be a three-dimensional lattice consisting of connecting voids of variable sizes and shapes, through which fluids in passing follow paths of least resistance along irregular or zigzag courses.

The size and structure of pores exercise an important influence on the life span of structural clay products when exposed to weather conditions, especially in climates of excessive moisture and severe freezing:

Freezing and thawing tests as means of judging certain weatherresisting properties of structural clay products have been recognized both in the United States and abroad by a large number of investigators, as indicated by the numerous reports appearing in the literature. $^{2}$

The number of freezing and thawing cycles which structural clay products will undergo without showing signs of failure depends upon numerous well-recognized factors, such as:

1. Different modifications of the test procedure.

2. Kind of clay used in making the product.

3. Method of forming.

4. Heat treatment.

5. Soundness and uniformity of structure.

6. Hardness and mechanical strength.

7. Degree of moisture saturation, or "saturation coefficient."

8. Pore structure.

Certain properties associated with porous structure have an important bearing on the life of structural clay products, but they have

\footnotetext{
${ }^{1}$ Laws of the rectilinear flow of ground water through a soil. Annual Report, U. S. Geol. Survey V, 19 pt. 2, 305-17 (1897-8).

2 Douglas $\mathrm{E}$. Parsons, Bibliography on the weathering of structural clay products, Proc. Am. Soc. Testing Materials 31, pt. 2, 825 (1931).
} 
received scant attention heretofore. This investigation was undertaken to obtain data on these properties and on their relation to failure of bricks as a result of freezing and thawing.

\section{MATERIALS AND PROPERTIESTSUDIED}

\section{SELECTION OF SPECIMENS}

Seven series of bricks, representing products of five different manufacturers, were selected for the investigation. The bricks, which are listed in table 1, were selected by visual inspection for their apparent freedom from defects; and they represent a wide range in porosity, difference in raw materials (clay or shale) used for making the products, and difference in method of manufacture. Two plasterof-paris slabs were also included for comparison in tests for permeability to air.

TABLE 1.-Bricks included in the investigation

\begin{tabular}{|c|c|c|c|c|}
\hline Series & $\begin{array}{c}\text { Number of } \\
\text { bricks }\end{array}$ & Material & Method of forming & Kiln treatment \\
\hline $\begin{array}{l}D \\
E \\
F \\
G \\
H \\
\\
K \\
K\end{array}$ & $\begin{array}{r}10 \\
10 \\
7 \\
11 \\
10 \\
10 \\
10\end{array}$ & $\begin{array}{l}\text { Clay- } \\
\text { Shale- } \\
\text { Clay-- } \\
\text { Shale } \\
\text { Clay do }\end{array}$ & $\begin{array}{l}\text { Soft mud } \\
\text { Stiff mud }{ }^{1} \\
\text { do do } \\
\text { Dry press. }\end{array}$ & $\begin{array}{l}\text { Soft burn. } \\
\text { Hard burn. } \\
\text { Medium burn. } \\
\text { Soft burn. } \\
\text { Hard burn. } \\
\text { Do. } \\
\text { Medium burn. }\end{array}$ \\
\hline
\end{tabular}

1 All stiff-mud bricks were side-cut.

\section{PROPERTIES DETERMINED}

The physical properties investigated were:

1. Percentage of porosity (exclusive of sealed pores). ${ }^{3}$ a. Bulk volume.

b. Solid volume (including sealed pores).

2. Variation in porosity within a brick.

3. Permeability to air and water.

4. The flow of air through two members in series.

5. Mean effective radius and number of capillaries.

6. Saturation coefficient.

7. Effect of freezing and thawing on the saturation coefficient.

8. Resistance to failure by repeated freezing and thawing.

\section{METHODS AND APPARATUS}

\section{PREPARATION OF THE SPECIMENS}

The bricks were ground to a thickness of approximately $2 \frac{1 / 16}{} \mathrm{in}$. to remove any hard or "glaze-like" skin formed during the kiln treatment and to obtain approximately parallel faces for the permeability determinations.

${ }^{3}$ The sealed pores were included in the solid volume, inasmuch as they are inactive with respect to permeability and water absorption. 


\section{POROSITY}

\section{(a) DEFINITION OF POROSITY}

The porosity ${ }^{4}$ is defined by the difference between the bulk volume, $V_{b}$, and the solid volume, $V_{s}$, expressed as a percentage of the bulk volume according to the equation

$$
V=\frac{100\left(V_{b}-V_{a}\right)}{V_{b}}
$$

(b) BULK VOLUME

The bulk volume was obtained by means of a mercury volumeter in which the volume of the specimen was determined from the weight and density of the mercury displaced. The volumeter is similar in principle to one frequently used for measuring volumes of small laboratory specimens, but was modified in design to be suitable for determining volumes up to and including specimens the size and shape of a brick. The specimen holder (fig. 1) is provided with points which make contact with the brick in such a manner that the brick is immersed with two faces vertical and four at 45 degrees to horizontal in order to prevent entrapping air.

Before the specimen is introduced, the system is balanced by adding sufficient counterweight to immerse the holder and maintain it with the balancing mark contacting the surface of the mercury. The holder with its supporting frame is then raised, the specimen inserted, and sufficient weight added to the pan to immerse the specimen with the balancing mark again contacting the surface of the mercury.

The sensitivity of the mercury volumeter is of a high order, inasmuch as the addition of $0.1 \mathrm{~g}$, after the system is balanced, sinks the balancing mark below the surface of the mercury.

The bulk volume of the brick was calculated from the equation

$$
V_{o}=\frac{(G+g)}{D}
$$

where $V_{b}$ is the bulk volume $\left(\mathrm{cm}^{3}\right), G$ is the weight (grams) added to the pan, $g$ is the weight (grams) of the specimen in air, $D$ is the density (grams per cubic centimeter) of mercury at the temperature of the determination.

\section{(c) SOLID VOLUME}

The solid volume was determined by means of a gas-expansion volumenometer. After consideration of various types recommended by different investigators, a volumenometer was constructed which operates on the principle of a porosimeter described by McGee. ${ }^{5}$ It is simple in design, requires no vacuum pump, and is rapid in operation. In the design of the volumenometer (fig. 2), a number of refinements

${ }_{4}$ Two methods generally employed for the determination of porosity are: (1) Saturating the specimen with a liquid and expressing the porosity in percentage of the ratio of the volume of liquid absorbed to the bulk volume of the specimen; (2) using the gas-expansion method for determination of the solid volume and expressing the porosity as the difference between bulk and solid volumes in percentage of the bulk volume. The porosity values obtained by the liquid-saturation method may be appreciably lower than those obtained by the gas-expansion method, because of inability of the liquid to completely fill the open pores, more especially those of microscopic size. Washburn and Bunting (see Porosity; VI. Determination of porosity by the method of gas expansion, J. Am. Ceram. Soc. 5, No. 2 (1922), table IX, p. 127) have shown that the porosity obtained by the water-saturation method for a stoneware clay fired to cone 10 was 0.8 percent less than that obtained by the gas-expansion method, and for a red-burning clay fired to cone 03 the porosity was 5.4 percent less than that obtained by the gas-expansion method. The gas-expansion method appears to be preferable and, therefore, was used in this investigation for the porosity determinations.

s'Several gas expansion porosimeters, J. Am. Ceram. Soc. 9, No. 12,817 (1926). 
were introduced to facilitate operation and to make possible readings of a comparatively high degree of accuracy. The volume of the specimen chamber, including that of the connecting tube up to the mark $B$, was determined by means of four chromium-plated steel standardizing blocks ${ }^{6}$ whose combined volume is $1,042.1$ $\mathrm{cm}^{3}$. The volume of the chamber (representing: the average of 20 determinations) is $1,451.8$ $\mathrm{cm}^{3}$, and the volume of the expansion bulb (between marks $B$ and $D)$ is $244.0 \mathrm{~cm}^{3}$.

The manometer is made of 8-mm-bore glass tubing which gives menisci of sufficiently flattened surfaces so that good check readings are obtainable. The scale for reading the mercury height, $h$, is graduated in millimeters on a mirror by means of which readings can be made (with the aid of a reading: glass) to approximately \pm 0.1 $\mathrm{mm}$. A chain counterbalance, $G$ (fig. 2), is provided for ease of operation in raising and lowering the mercury bulb, and the supporting clamp for holding the mercury bulb is provided with a vernier for adjusting the mercury height at the leveling marks.

With the stopcock open to atmospheric pressure, $H$ (mm $\mathrm{Hg}$ ), the mercury bulb is raised until the two menisci are at the level $B$ (fig. 2). The stopcock is then closed and the mercury bulb is lowered until the meniscus on the right is at the level $D$. The initial volume of the chamber, $A$, minus the volume of solids in the brick $\left(1451.8-V_{s}\right)$ is thereby increased by the volume ( 244.0 $\mathrm{cm}^{3}$ ) of the expansion bulb, $C$,

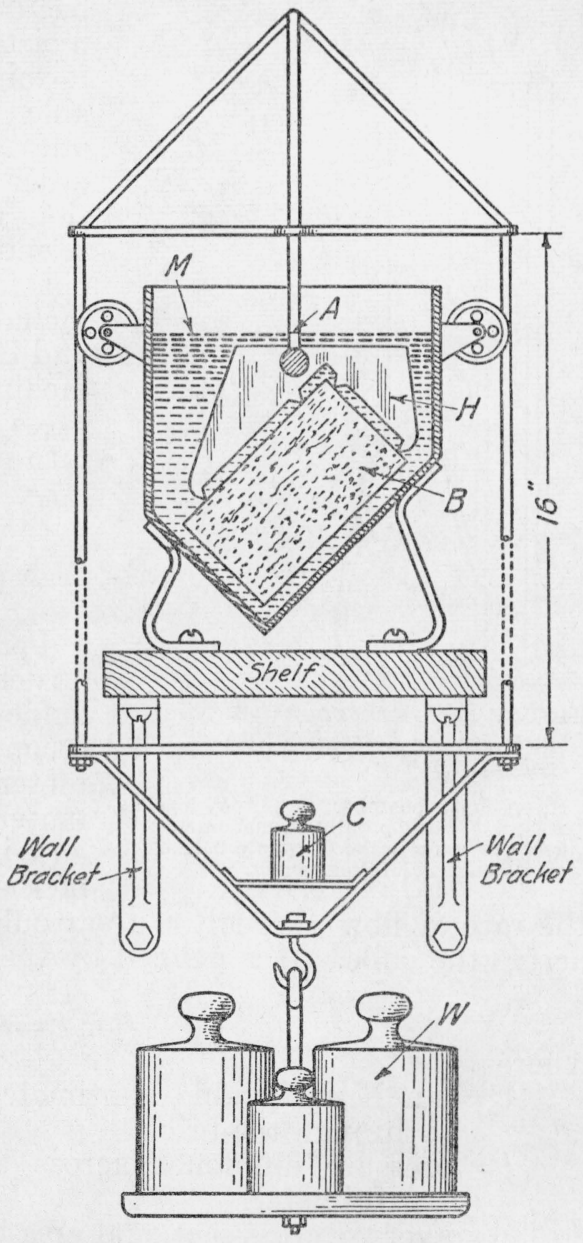

FIGURE 1.-Sectional view of mercury volumeter for determination of bulk volume.

$A$, balancing mark; $M$, mercury; $H$, specimen holder $B$, specimen; $C$, counterweight; $W$, balancing weight.

while the pressure is decreased by $h(\mathrm{~mm} \mathrm{Hg}$, corrected to correspond to $H$ ). Since the product of pressure and volume is constant,

or

$$
H\left(1451.8-V_{s}\right)=(H-h)\left(1451.8-V_{s}+244.0\right)
$$

$$
V_{s}=1695.8-244.0 \frac{H}{h}
$$

- The chromium-plated blocks and the air-expansion bulb were calibrated for volume by the National Bureau of Standards, Division of Weights and Measures. 


\section{(d) POROSITY OF DIFFERENT SECTIONS OF A BRICK}

The porosity as determined according to eq 1 represents the mean porosity of a brick as a unit. The porosity, however, differs at various

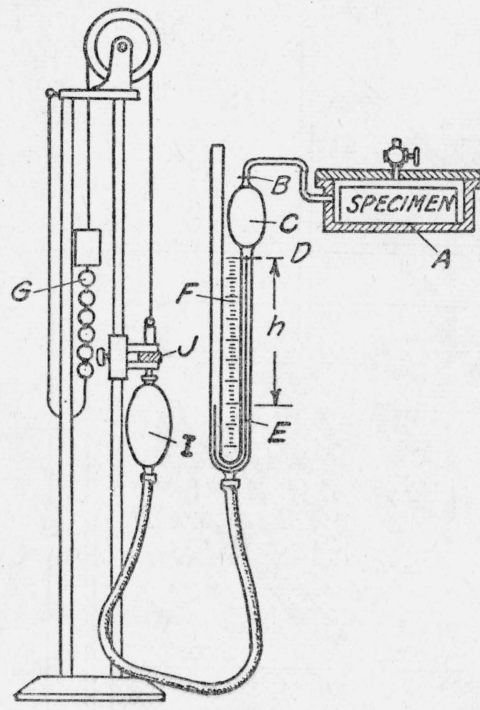

FIGURE 2.-Air expansion volumenometer for determination of solid volume.

$A$, specimen chamber; $B$ and $L$, leveling marks; $C$, expansion bulb; $E$, manometer; $F$, mirror graduated scale; $G$, counterbalance; $I$, mercury bulb; $J$, leveling vernier.

the rate of flow through a 1 om across the cube. It is defined by the equation

where

$$
f \text { or } f^{\prime}=Q T / A P,
$$

$Q=$ number of cubic centimeters of fluid passing per second through the brick.

$P=$ pressure difference across the brick in grams per square centimeter.

$A=$ average cross-sectional area in square centimeters over which flow takes place.

$T=$ thickness of the brick, in centimeters, through which transmission of the fluid occurs.

For air, the permeability is designated by $f$, and that for water by $f^{\prime}$.

\section{(b) APPARATUS FOR DETERMINING AIR PERMEABILITY}

The permeameter for determination of air permeability is similar to that described by Ketcham, Westman, and Hursh. ${ }^{7}$ As a precautionary measure to prevent possible obstruction to flow, the clamps which were used for holding the specimen against the felt seal were replaced by a weight (fig. 4) resting on a platform, the four legs of

${ }^{7}$ The Measurement of the Permeability of Ceramic Bodies, Univ. of Ill. Eng. Exp. Sta. Bull. No. 50, p. 14-21 (Aug. 17, 1926). 
which were pointed at the lower ends for making contact with the brick. The weight also insures a constant load on the felt seal. A kerosene manometer, $F$, was added for measuring those pressure drops across the specimen which were too high for measurement by means of the inclined manometer, $E$.

Air maintained at a constant pressure by the pressure regulator, $H$ (fig. 4), is forced through a capillary flowmeter in series with the specimen and is discharged at atmospheric pressure. The calibrated manometer, $G$, of the flowmeter indicates the rate of flow through the specimen at a pressure difference shown by the manometer $F$ (or $E$ ).

The capillary flowmeter was provided with four interchangeable capillaries of different bores for determination of rates of flow over a wide range of permeability. The capillaries were calibrated for air flow in cubic centimeters per second by means of the "standardizing flowmeter" designed by F. T. Carson. ${ }^{8}$ The calibrations of the capillaries were made over pressures within safe limits below those causing turbulent flow.

(1) Air transmission of two members in series. When the air permeabilities of two different bricks are $f_{1}$ and $f_{2}$, respectively, and their respective thicknesses

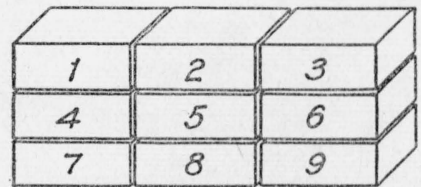

Frgure 3.-Method of sectioning brick for determination of variation in porosity. $T_{1}$ and $T_{2}$, then the air transmission, or "air conductance," of the two bricks in series may be calculated by an equation analogous to that used for determining the electrical conductance of two conductors in series. In brick 1, the air transmission is the air flow in cubic centimeters per second per square centimeter with pressure difference of $1 \mathrm{~g} / \mathrm{cm}^{2}$, or $f_{1} / T_{1}$. Likewise, in brick 2 , the air transmission is $f_{2} / T_{2}$.

When two electrical conductors are joined in series, the conductance through the whole is the product of the two conductances, $C_{1}$ and $C_{2}$, divided by their sum-that is, $\left(C_{1} C_{2}\right) /\left(C_{1}+C_{2}\right)$. By analogy, we write $f_{1} / T_{1}$ instead of $C_{1}$ and $f_{2} / T_{2}$ instead of $C_{2}$, giving the equation

$$
F=\frac{f_{1} f_{2}}{f_{1} T_{2}+f_{2} T_{1}}
$$

where $F$ is the air transmission through the two bricks in cubic centimeters per second per square centimeter for a pressure difference of $1 \mathrm{~g} / \mathrm{cm} .^{2}$

As a means of determining the agreement between calculated and experimental results for obtaining the air transmission, $F$, for units composed of different combinations of two members in series, tests were made using five different members to form the units, each member having an area of $81 / 16$ by $3 \frac{3}{4}$ in. and of different thicknesses. Two of the members were cut from a red dry-press brick, one from a buff dry-press brick, and two were plaster-of-paris slabs. The permeabilities were first determined separately for each member, and those for the different combinations were then determined by means of the assembly shown in figure 5, representing a cross-sectional view of the permeameter box and two members in series forming a unit.

${ }^{8} \mathrm{~A}$ sensitive instrument for measuring the air permeability of paper and other sheet materials, BS J. Research 12,578 (1934) RP681. 
(c) APPARATUS FOR DETERMINING WATER PERMEABILITY

The permeameter designed for the determination of water permeability is shown schematically in figure 6. This apparatus is also suitable for measuring air permeability when the water is emptied from tank $D$ and air driers $Z$ are connected. The specimen, $A$, is sealed in the permeameter box, $B$, by means of a rectangular rubber tube, $C$, inflated to a pressure ${ }^{9}$ of $70 \mathrm{lb} / \mathrm{in}^{2}$.

For water permeability determinations, the tank, $D$, is filled with water and air pressure applied to produce flow of water through the specimen. The number of cubic centimeters of water flowing through the specimen per second is obtained by determining the number of cubic centimeters of air required for its displacement.

The pressure regulator, $E$, consisting of two cylinders connected

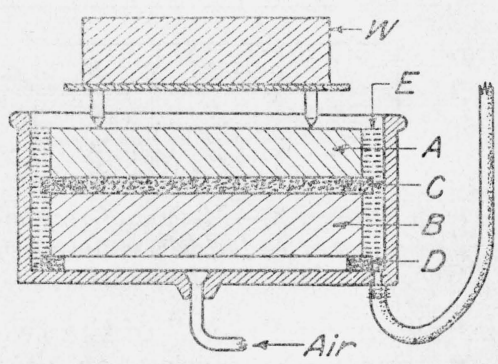

FIGURE 5.-Method of sealing specimens for determination of the air conductance of a unit composed of two members in series.

$A$ and $B$, two members composing the unit; $C$, felt sealing pad; $D$, felt sealing gasket; $E$, mercury seal; $W$, sealing weight. to a 40 -gal tank, $F$, is provided with a small and sensitive cut-off valve, $G$, actuated by a float operating in kerosene. With the valve, $H$, closed, air is admitted to the accumulator, $I$, through two pressure reducers, $J$ and $K$. Valves $L$ and $M$ are closed and $N, O, P$, and $R$ are opened. The pressure is allowed to build up in the pressure regulator and tank, $F$, until the desired working pressure as indicated by the pressure gage, $S$, is obtained. Valves $R$ of the regulator and $P$ of the by-pass are then closed, allowing the air to pass through the capillary, $T$, of the flowmeter and into the water tank. The air pressure is then regulated by the pressure reducer, $K$, so that approximately two bubbles of air per second escape through water in the glass indicator, $U$. After the pressure has been properly adjusted, it remains substantially constant and the system is allowed to stand until the arms of the manometer, $V$, come to rest at the same level. $H$ is then opened to allow water to flow through the specimen.

The capillary of the flowmeter was calibrated in cubic centimeters per second of air flow by means of the standardizing flowmeter. ${ }^{10}$ The gage, $W$, is provided with a millimeter scale to indicate the height of water in the tank above the water level above the specimen.

Two manometers are provided for determining the drop in pressure across the specimen. These are a kerosene manometer, $X$, for determining flow pressures up to $120 \mathrm{~g} / \mathrm{cm}^{2}$, (equivalent to about $9 \mathrm{~cm}$ of mercury) and a mercury manometer, $Y$, for pressures up to 1,615 $\mathrm{g} / \mathrm{cm}^{2}$. The flow pressure is the sum of the pressure obtained by means of the manometer reading and the pressure of the waterhead as indicated by the water gage, $W$.

\footnotetext{
- Air-permeability determinations, when made on several specimens with the mercury seal and also with the inflated rubber seal, checked at a sealing air pressure of about $70 \mathrm{lb} / \mathrm{in}^{2}$. The walls of the sealing tube were very thick, which required a pressure of $70 \mathrm{lb} / \mathrm{in} .^{2}$ to produce the same sealing effect as that of the mercury.

10 See footnote 8, p. 717 .
} 


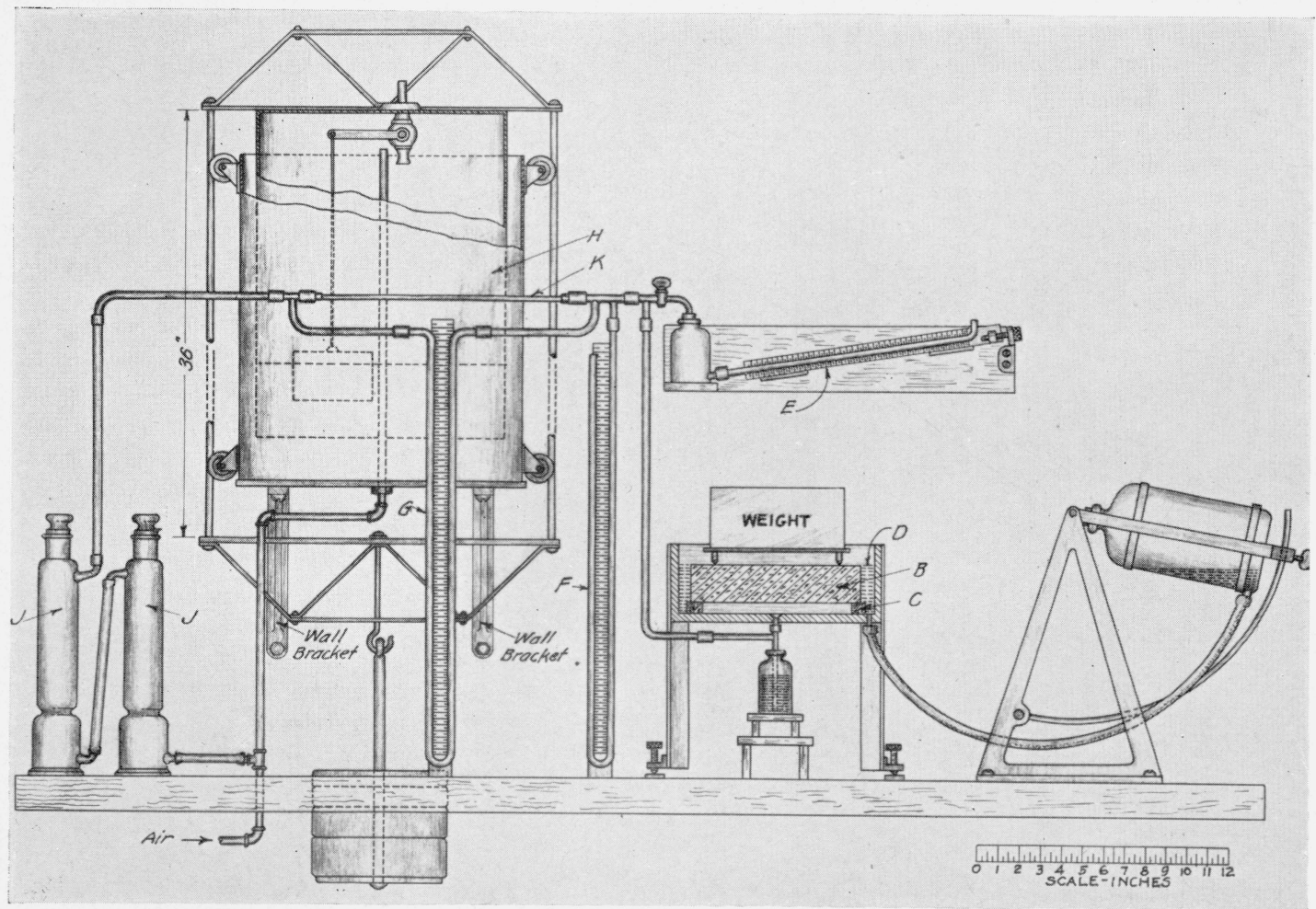

FiguRe 4.-Air permeameter.

$B$, specimen; $C$, felt seal; $D$, mercury seal; $E$, inclined manometer; $F$, kerosene manometer for determination of pressure drop across the specimen; $G$, flowmeter manometer; $H$, combination accumulator and pressure regulator; $J, J$, drying towers; $K$, interchangeable flowmeter capillary. 


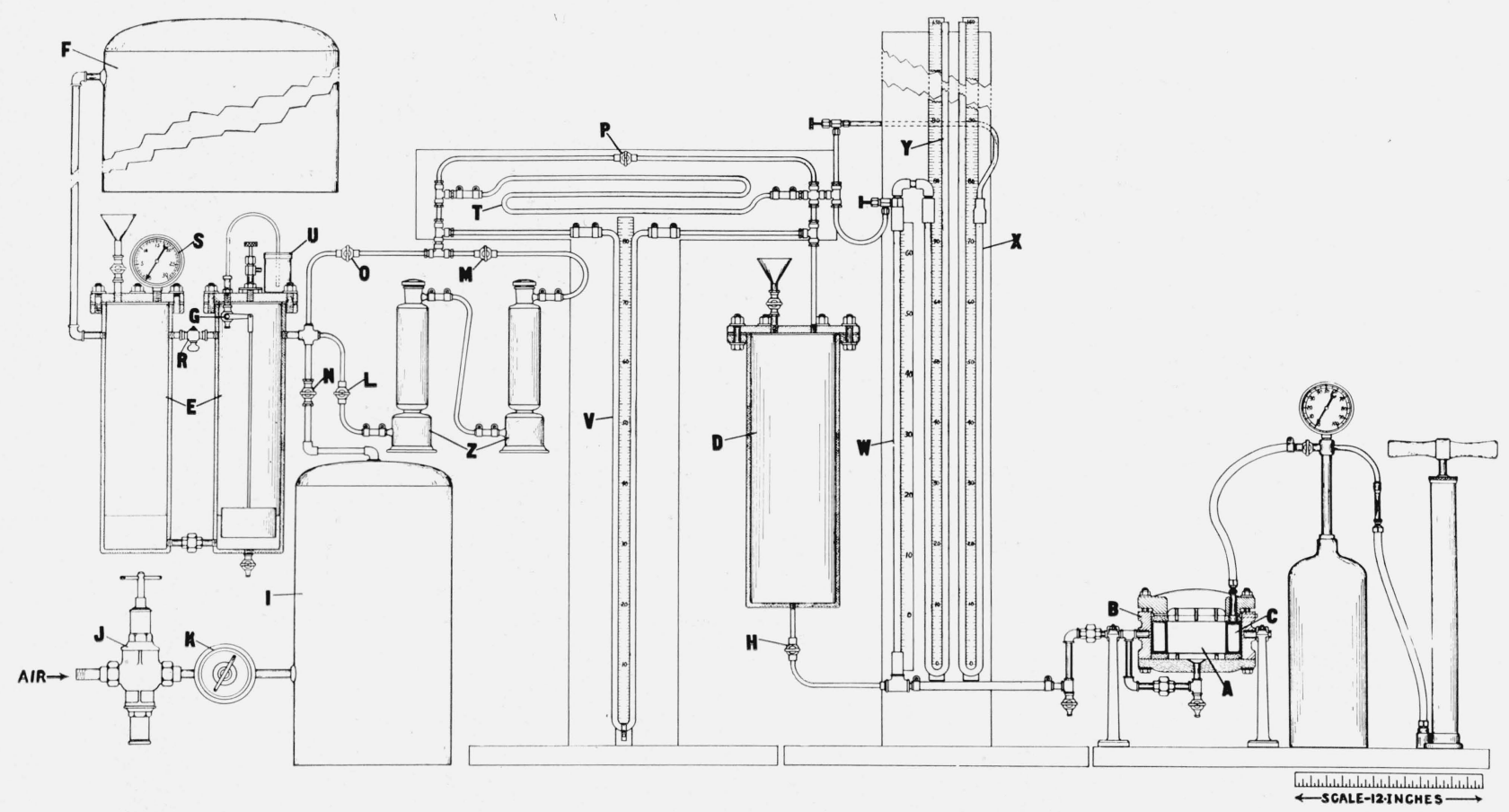

Figure 6.-Water permeameter. Described on p. 718 


\section{DETERMINING MEAN EFFECTIVE RADIUS AND NUMBER OF CAPILLARIES}

The volume rate of discharge of a gas passing through a porous earthy material is proportional to the pressure difference between the parallel planes between which the gas travels. The behavior is, therefore, analogous to the flow through a long cylindrical capillary passage which can be described by the Poiseuille equation.

Although the Poiseuille equation cannot be applied to the actual brick, one can, however, visualize an imaginary brick, the pore system of which is made up of $N$ identical, parallel, uniformly distributed, cylindrical capillary passages with a radius $r$, and length $T$, which has the same air permeability as the actual brick. To this imaginary brick, one can apply the Poiseuille equation and develop expressions for $r$ and $N$ which serve a useful purpose in correlation with the experimental data, even though the calculated $r$ values are probably somewhat too small and the $N$ values too large, since the lengths of the actual air passages must be greater than $T$ in the actual brick. The equations for evaluating $r$ and $N$ are substantially the same as those employed by Clews and Green. ${ }^{11}$ When determined on the basis of a unit cube $\left(1 \mathrm{~cm}^{3}\right)$ these equations are:

where

$$
\begin{aligned}
r & =0.012(f / V)^{1 / 2} \\
N & =21.7\left(V^{2} / f\right)
\end{aligned}
$$

$r=$ mean effective capillary radius in centimeters.

$N=$ number of capillaries of radius $r$, per square centimeter of surface.

$f=$ air permeability (as defined by eq 4 ).

$V=100\left(\pi r^{2} N\right)$, the percentage of porosity.

\section{FREEZING AND THAWING TESTS}

(a) PROCEDURE

Inasmuch as the method employed in making the freezing and thawing tests has a bearing on the number of freezing and thawing cycles required to cause failure of the bricks, a method was adopted which would give comparable results and reduce the time element to a minimum.

The bricks were first partially saturated by immersion for 48 hours in water at room temperature, after which each cycle consisted in freezing the bricks standing on edge in $1 / 4$ in. of water, then thawing by immersion for 4 hours in water at room temperature. No opportunity was allowed for the bricks to dry between cycles, and only six cycles per week were completed, since the bricks were allowed to remain in the freezing chamber over Sundays.

\section{(b) SATURATION COEFFICIENT}

The percentage volume of water, $W$, absorbed by the brick at each step in the above process is determined by removing the brick from the water, blotting the surface with a towel, and determining the weight of water absorbed, then converting the weight into percentage

11 F. H. Olews and A. J. Green, The permeability of refractory materials to gases, Part I. Trans. Eng. Ceram. Soc. 32, $317(1932-3)$. 
by volume of the bulk volume of the brick. The saturation coefficient, $S$, is then defined by the equation

$$
S=W / V
$$

in which $W$ is the volume in percent of water absorbed and $V$ has the same significance as in the previous equations. The saturation coefficient obtained by partial saturation of the brick by 48 hours' immersion at room temperature is herein termed the "initial" saturation coefficient and denoted by $S_{1}$.

\section{(c) INCREASE IN SATURATION COEFFICIENT WITH REPEATED FREEZING AND THAWING}

Since the volume of water absorbed increases with successive thawings by immersion in water, the saturation coefficients of the bricks at failure were determined on the basis of their original pore volumes for comparison with their respective initial saturation coefficients. Also, as a means of determining the rate of this increase, the saturation coefficients of the members of series $D$ and $E$ were determined for each freezing cycle after the bricks had thawed and attained room temperature.

\section{RESULTS AND DISCUSSION}

\section{VARIATION IN POROSITY WITHIN A BRICK}

The percentage porosities obtained on the different sections of bricks $F 5, G 8, H 9, J 10$, and $K 3$ are given in tables 2 and 3 . The data obtained on the sections indicate that there is no definite correlation among the specimens as to location of sections of highest, medium, and lowest porosities. The difference between the average porosity obtained on the basis of the total bulk and solid volumes of the sections for each brick, and the original porosity determined before cutting may be due to materials lost in the cutting. The spread in the variation of the porosities for the bricks ranged from 11.6 percent in $J 10$ to 48.4 percent in G8.

Obviously, the tendency of a brick is to fail at its weakest point when subjected to freezing and thawing tests. Therefore, variation in porosity evidently exercises an influence on the resistance to frost action inasmuch as permeability, saturation coefficient, and the values calculated for the effective size and the number of capillaries are partly dependent on porosity.

TABLE 2.-Variation in porosity, $V$, in different sections of the bricks

\begin{tabular}{|c|c|c|c|c|c|}
\hline \multirow{2}{*}{ Section number 1} & \multicolumn{5}{|c|}{ Brick number } \\
\hline & F5 & $G 8$ & H9 & $J 10$ & $K S$ \\
\hline${ }^{1}$ & $\begin{array}{l}28.2 \\
28.6 \\
29.4 \\
31.6 \\
31.6 \\
31.3 \\
27.8 \\
27.1 \\
27.0\end{array}$ & $\begin{array}{l}17.3 \\
20.6 \\
21.6 \\
22.2 \\
22.4 \\
27.7 \\
20.6 \\
20.8 \\
20.8\end{array}$ & $\begin{array}{l}13.1 \\
14.6 \\
13.8 \\
12.1 \\
11.6 \\
13.6 \\
11.9 \\
12.9 \\
11.7\end{array}$ & $\begin{array}{l}24.6 \\
24.7 \\
24.3 \\
23.5 \\
23.2 \\
24.9 \\
24.9 \\
26.0 \\
24.8\end{array}$ & $\begin{array}{l}31.9 \\
30.0 \\
33.7 \\
31.1 \\
28.6 \\
27.6 \\
30.0 \\
28.8 \\
28.2\end{array}$ \\
\hline $\begin{array}{l}\text { A verage } V \text {. } \\
\text { Original } V- \\
\text { Spread }{ }^{2}-\end{array}$ & $\begin{array}{l}29.2 \\
29.6 \\
15.9\end{array}$ & $\begin{array}{l}21.6 \\
20.6 \\
48.4\end{array}$ & $\begin{array}{l}12.8 \\
12.5 \\
23.4\end{array}$ & $\begin{array}{l}24.5 \\
24.8 \\
11.6\end{array}$ & $\begin{array}{l}30.0 \\
30.0 \\
20.3\end{array}$ \\
\hline
\end{tabular}

1 See figure 3.

2 Percentage difference between maximum and minimum porosities of the different bricks. 
TABLE 3.-Ranking position of porosities of the corner, middle, and center sections

\begin{tabular}{|c|c|c|c|c|c|}
\hline \multirow{2}{*}{ Sections } & \multicolumn{5}{|c|}{ Brick number } \\
\hline & F5 & G8 & H9 & J10 & $K 3$ \\
\hline Average, 4 corners.... & Low & Low ......... & Medium _... & Medium _... & High. \\
\hline A verage, 4 middles................... & Medium - & High & High & High.......... & Medium. \\
\hline Center & High & Medium .... & Low & Low & Low. \\
\hline
\end{tabular}

\section{PERMEABILITY TO AIR AND WATER}

The movement of air through the bricks conformed to the laws of capillary flow in all cases except for brick $H 2$, in which the permeability decreased with increase in pressure difference, conforming neither to capillary flow nor to flow through orifices, but apparently affected by a combination of the two. However, constant water permeability values were not obtained, inasmuch as consecutive determinations under continuous flow showed an increase in permeability with time of flow for some bricks, while for others permeability decreased with time of flow.

The water permeabilities determined consecutively over a period of time for the different members ${ }^{12}$ of series $F, G, H, \bar{J}$, and $K$ are presented in table 4, arranged in sequence of their $r$ values. The first reading of the manometers for obtaining the initial permeability was made after the brick became thoroughly wetted and covered with a uniform layer of approximately $2 \mathrm{~mm}$ of water, which required about 5 to 25 minutes for bricks ranging from high to low permeabilities, respectively. The permeabilities given in the table represent data obtained from readings made hourly after the first reading for all bricks except those of series $J$ and $K$, where the readings were made at 20-minute intervals.

Table 4 shows that the specimens exhibit change in water permeability with time. Increase in water permeability with time of flow occurs with all members of series $F$ and $G$ except $G Q$, and decrease with time for GQ and all members of series $H, J$, and $K$ with the possible exception of $H 5$, the permeability of which is substantially constant.

Bartell, ${ }^{13}$ in reporting his results on the water permeability of porcelain disks, attributes the decline in water permeability to progressive clogging by small particles mechanically broken off and carried into the pores by movement of the water. Muskat ${ }^{14}$ considers that:

"One very common cause of the plugging of a porous medium upon continuous flow of a liquid, as water, through it, is the evolution of air or gas dissolved in the liquid. The gas becomes entrapped in the pores of the medium in the form of small bubbles and may decrease the resultant permeability of the liquid to a small fraction of its original value."

Since the tests herein reported were made with nondeaired water at room temperatures, Muskat's explanation appears logical for those bricks of diminishing permeability.

\footnotetext{
12 No water permeabilities were determined for series $D$ and $E$ nor for bricks $F 1, H Q$, and $H 7$.

13 F. E. Bartell, The permeability of porcelain and copper ferrocyanide membranes, J. Phys. Chem. 15, 664 (1911)

${ }_{14}$ M. Muskat, The flow of homogeneous fluids through porous media, p. 90 (MeGraw-Hill Book Co., Inc., New York, N. Y., 1937).
} 
TABLE 4.--Relation of mean effective capillary radius, $r$, to the water permeability, $f^{\prime}$, of bricks

\begin{tabular}{|c|c|c|c|c|c|c|}
\hline \multirow[b]{2}{*}{ Brick number } & \multicolumn{6}{|c|}{ Reading } \\
\hline & $\begin{array}{c}\text { Ist } \\
f^{\prime} \times 10^{7}\end{array}$ & $\stackrel{2 \mathrm{~d}}{f^{\prime} \times 10^{7}}$ & $\stackrel{3 \mathrm{~d}}{f^{\prime} \times 10^{7}}$ & $\underset{f^{\prime} \times 10^{7}}{\stackrel{\text { th }}{7}}$ & $\begin{array}{c}5 \text { th } \\
f^{\prime} \times 10^{7}\end{array}$ & $r$ \\
\hline $\begin{array}{l}F 3 \\
F 5 \\
G 7 \\
F 4 \\
G 4\end{array}$ & $\begin{array}{l}47 \\
49 \\
70 \\
58 \\
75\end{array}$ & $\begin{array}{l}50 \\
53 \\
98 \\
68 \\
97\end{array}$ & $\begin{array}{r}57 \\
62 \\
122 \\
69 \\
121\end{array}$ & $\begin{array}{r}64 \\
67 \\
139 \\
87 \\
141\end{array}$ & $\begin{array}{r}66 \\
75 \\
88 \\
171\end{array}$ & $\begin{array}{r}\text { Microns } \\
0.95 \\
.96 \\
1.27 \\
1.29 \\
1.33\end{array}$ \\
\hline $\begin{array}{l}G 1 \\
G 10 \\
G 6 \\
G 11 \\
G 5\end{array}$ & $\begin{array}{r}100 \\
72 \\
70 \\
72 \\
75\end{array}$ & $\begin{array}{r}134 \\
82 \\
71 \\
85 \\
84\end{array}$ & $\begin{array}{r}153 \\
88 \\
79 \\
98 \\
98\end{array}$ & $\begin{array}{r}173 \\
102 \\
81 \\
116 \\
107\end{array}$ & $\begin{array}{r}186 \\
106 \\
84 \\
129 \\
125\end{array}$ & $\begin{array}{l}1.46 \\
1.49 \\
1.54 \\
1.55 \\
1.63\end{array}$ \\
\hline $\begin{array}{l}\text { FE } \\
G 9 \\
G 8 \\
G 6 \\
H 5\end{array}$ & $\begin{array}{r}70 \\
106 \\
97 \\
83 \\
78\end{array}$ & $\begin{array}{r}74 \\
128 \\
133 \\
90 \\
75\end{array}$ & $\begin{array}{r}80 \\
164 \\
165 \\
100 \\
77\end{array}$ & $\begin{array}{r}194 \\
179 \\
113 \\
79\end{array}$ & $\begin{array}{r}81 \\
121 \\
78\end{array}$ & $\begin{array}{l}1.65 \\
1.66 \\
1.75 \\
1.76 \\
1.82\end{array}$ \\
\hline $\begin{array}{l}G 3 \\
F^{3} \\
G 2 \\
H 4 \\
H S\end{array}$ & $\begin{array}{l}163 \\
110 \\
258 \\
140 \\
175\end{array}$ & $\begin{array}{r}212 \\
107 \\
225 \\
89 \\
134\end{array}$ & $\begin{array}{r}255 \\
124 \\
207 \\
82 \\
133\end{array}$ & $\begin{array}{r}276 \\
122 \\
214 \\
80 \\
123\end{array}$ & $\begin{array}{r}281 \\
129 \\
218 \\
79 \\
122\end{array}$ & $\begin{array}{l}1.89 \\
\text { 1. } 98 \\
\text { 2. } 36 \\
\text { 2. } 66 \\
2.81\end{array}$ \\
\hline $\begin{array}{l}H 8 \\
K 5 \\
H 6 \\
K 6_{2} \\
K_{4}\end{array}$ & $\begin{array}{r}209 \\
951 \\
193 \\
1,160 \\
1,040\end{array}$ & $\begin{array}{r}162 \\
902 \\
181 \\
1,060 \\
969\end{array}$ & $\begin{array}{r}131 \\
863 \\
178 \\
1,060 \\
948\end{array}$ & $\begin{array}{r}128 \\
845 \\
168 \\
1,040 \\
943\end{array}$ & $\begin{array}{r}119 \\
869 \\
1,030 \\
938\end{array}$ & $\begin{array}{l}2.97 \\
3.00 \\
3.05 \\
3.14 \\
3.16\end{array}$ \\
\hline $\begin{array}{l}K 8 \\
K B \\
K \gamma \\
K 6 \\
H 1 \\
\end{array}$ & $\begin{array}{l}1,100 \\
1,010 \\
1,140 \\
1,150 \\
219\end{array}$ & $\begin{array}{r}1,030 \\
927 \\
1,060 \\
1,060 \\
173\end{array}$ & $\begin{array}{r}1,020 \\
909 \\
1,030 \\
1,060 \\
169\end{array}$ & $\begin{array}{r}1,010 \\
894 \\
1,060 \\
1,040 \\
164\end{array}$ & $\begin{array}{r}1,020 \\
881 \\
1,010 \\
1,050\end{array}$ & $\begin{array}{l}\text { 3. } 21 \\
3.23 \\
3.25 \\
3.30 \\
\text { 3. } 46\end{array}$ \\
\hline $\begin{array}{l}K 9 \\
K 10 \\
H 9 \\
H 10 \\
K 1\end{array}$ & $\begin{array}{r}1,410 \\
1,320 \\
294 \\
238 \\
1,620\end{array}$ & $\begin{array}{r}1,330 \\
1,250 \\
240 \\
190 \\
1,570\end{array}$ & $\begin{array}{r}1,280 \\
1,200 \\
215 \\
178 \\
1,590\end{array}$ & $\begin{array}{r}1,270 \\
1,190 \\
201 \\
167 \\
1,570\end{array}$ & $\begin{array}{r}1,280 \\
1,190 \\
220 \\
158 \\
1,590\end{array}$ & $\begin{array}{l}\text { 3. } 48 \\
\text { 3. } 50 \\
\text { 3. } 50 \\
\text { 3. } 51 \\
\text { 3. } 52\end{array}$ \\
\hline $\begin{array}{l}J \gamma^{\prime} \\
J S^{\prime} \\
J 6 \\
J 8 \\
J 9 \\
\end{array}$ & $\begin{array}{l}1,280 \\
2,120 \\
1,540 \\
1,550 \\
1,560\end{array}$ & $\begin{array}{l}1,170 \\
1,880 \\
1,400 \\
1,470 \\
1,470\end{array}$ & $\begin{array}{l}1,170 \\
1,800 \\
1,380 \\
1,450 \\
1,440\end{array}$ & $\begin{array}{l}1,140 \\
1,740 \\
1,310 \\
1,420 \\
1,450\end{array}$ & $\begin{array}{l}1,110 \\
1,710 \\
1,300 \\
1,380 \\
1,440\end{array}$ & $\begin{array}{l}3.88 \\
3.94 \\
3.97 \\
4.00 \\
4.05\end{array}$ \\
\hline $\begin{array}{l}J_{2} \\
J_{4} \\
J_{1} 0_{0} \\
J_{5}\end{array}$ & $\begin{array}{l}1,610 \\
1,840 \\
1,710 \\
2,110 \\
2,110\end{array}$ & $\begin{array}{l}1,550 \\
1,620 \\
1,600 \\
1,890 \\
2,040\end{array}$ & $\begin{array}{l}1,500 \\
1,570 \\
1,520 \\
1,810 \\
1,980\end{array}$ & $\begin{array}{l}1,490 \\
1,590 \\
1,500 \\
1,830 \\
1,900\end{array}$ & $\begin{array}{l}1,470 \\
1,520 \\
1,470 \\
1,790 \\
1,920\end{array}$ & $\begin{array}{l}4.17 \\
\text { 4. } 26 \\
4.32 \\
4.38 \\
4.49\end{array}$ \\
\hline
\end{tabular}

Increase in water permeability with time, however, occurred with bricks of the $F$ and $G$ series (except GR), and data of this nature have not been previously recorded to the authors' knowledge. The $r$ values of these bricks in which permeability increased are smaller than those in which permeability decreased under continuous flow; therefore, it would seem that clogging of the pores by small particles or by air would be more pronounced and cause a decrease rather than an increase in permeability. Progressive solution of the walls of the capillaries with consequent increase in their cross sections would explain such behavior, but the specimens are not of such a nature that solution would be probable. 
The average size of $r$ appears to effect a separation between increase and decrease in the rate of water permeability. With the exception. of specimen $H 5$ (where permeability is about constant), all bricks having $r$ 's less than 2 microns (table 4 ) gave increase in water permeabilities with time. Conversely, all bricks having $r$ 's greater than 2 microns exhibited decrease in permeability.

According to Poiseuille's equation, the ratio of the permeability of one fluid to that of another is inversely proportional to their respective viscosities. Therefore, when $n^{\prime}$ and $n$ are the respective viscosities of water and air, $f$ the permeability of air, and $f^{\prime}$ that of water, then

$$
n^{\prime} / n=f / f^{\prime}=a \text {, and }\left(f / f^{\prime}\right) / a=1 .
$$

Since the water permeability of a brick is continuously changing under continuous flow, its value is very indefinite. Mills ${ }^{15}$ noted the lack of agreement between the air and water permeabilities of bricks and states that this is probably explained by the "heterogeneous nature of the products and, as a consequence, the interrupting effects of surface tension."

As a means of determining the relation between the ratio of the air to the initial water permeabilities and $r$, the $f / f^{\prime}$ and also the $\left(f / f^{\prime}\right) / a$ values (where $a=55.5$ ) were determined for the average air permeabilities and the average initial water permeabilities for each of the $F$, $G, H, J$, and $K$ series. The results are shown in table 5 , arranged in sequence of their respective $r$ values. The data, though confined to rather narrow limits, indicate that $f / f^{\prime}$ is decreasing toward the value 55.5 and $\left(f / f^{\prime}\right) / 55.5$ toward unity as $r$ is increasing.

TABLE 5.-Relation between the ratio of air to water permeability and the capillary radius

\begin{tabular}{|r|r|r|r|r|}
\hline Series & $\begin{array}{r}\text { Number } \\
\text { of bricks }\end{array}$ & $f / f^{\prime}$ & $\left(f / f^{\prime}\right) / 55.5$ & $r$ \\
\hline$F$ & 6 & 572 & 10.3 & 1.37 \\
$G_{-}$ & 11 & 481 & 8.7 & 1.64 \\
$H$ & 10 & 410 & 7.4 & 2.97 \\
$K$ & 10 & 184 & 3.3 & 3.28 \\
\hline & 10 & 169 & 3.0 & 4.13 \\
\hline
\end{tabular}

From the data reported by Mills ${ }^{16}$ on air and water permeabilities of 12 miscellaneous bricks, the $\left(f / f^{\prime}\right) / 55.5$ values were determined. They show a range from 27.4 to 0.8 . The latter value indicates that the water permeability determined for one brick was greater than that of its air permeability.

The data for the water permeabilities, however, were calculated by Mills from the readings made "when the flow had reached a steady rate" and, therefore, they do not represent initial permeabilities.

As pointed out by Muskat, ${ }^{17}$ air dissolved in water produces erratic results in water-permeability tests. Whether the data here reported

15 E. O. Mills, The permeability to air and to water of some building bricks, Trans. Eng. Ceram. Soc. 33, 210 (1933-4).

10 See footnote 15

17 See footnote 14, p. 721. 
represent the actual water permeabilities of the bricks or whether they are affected by uncontrolled factors in the test method remains to be determined.

\section{FLOW OF AIR THROUGH TWO MEMBERS IN SERIES}

The permeabilities determined separately for the members are given in table 6 . The permeabilities of the units calculated according to eq 5 and those determined experimentally are given in table 7, where it is seen that the differences between the experimental and calculated permeabilities (column 4, table 7), which may be charged to experimental error and resistance to flow through the felt pad, $C$ (fig. 5) range from 0 to 0.49 percent. These differences are so small as to be negligible.

TABLE 6.-Thickness and permeability of the members composing the units

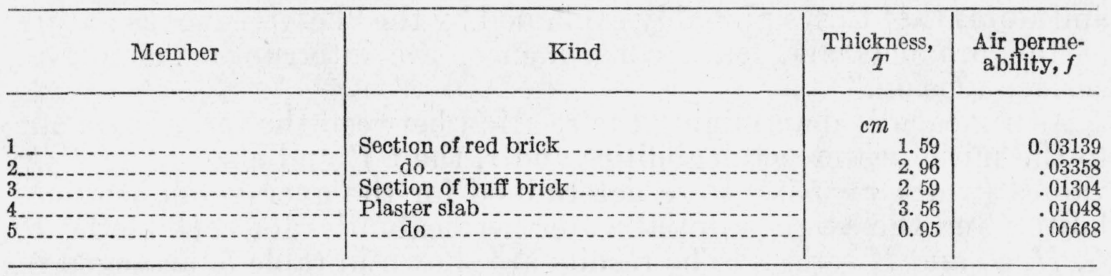

TABLE 7.-Comparison of the calculated and measured air transmission values of different units composed of two members in series

\begin{tabular}{|c|c|c|c|}
\hline Members forming units ${ }^{1}$ & $F$ Calculated & $\begin{array}{c}F \text { Deter- } \\
\text { mined }\end{array}$ & $\begin{array}{l}\text { Differ- } \\
\text { ence }\end{array}$ \\
\hline $\begin{array}{l}1 \text { and } 2 \\
1 \text { and } 3 \\
12 \text { and } 5 \\
1 \text { and } 4 \\
3 \text { and } 5\end{array}$ & $\begin{array}{l}0.00719 \\
.00404 \\
.00518 \\
.00434 \\
.00256 \\
.00293\end{array}$ & $\begin{array}{l}0.00718 \\
.00402 \\
.00517 \\
.00432 \\
.00256 \\
.00292\end{array}$ & $\begin{array}{r}\text { Percent } \\
0.14 \\
.49 \\
.19 \\
.46 \\
0.10\end{array}$ \\
\hline
\end{tabular}

1 See table 6.

\section{EFFECT OF FREEZING AND THAWING ON THE SATURATION COEFFICIENT}

The saturation coefficients determined after each cycle of freezing and thawing for the members of the $D$ and $E$ series, when plotted against the corresponding cycles of freezing and thawing up to 60 cycles, or until the bricks failed, produced graphs which are typical of that shown in figure 7 for brick D9. The curve can be represented fairly well by an equation of a hyperbola which, within the limits of the data, may be expressed by the empirical equation

$$
S=a-\frac{K}{b+C^{2}}
$$

where $S$ is the saturation coefficient, $C$ the cycle of freezing and thawing, and $a, b$, and $K$ are constants which are different for each brick. 

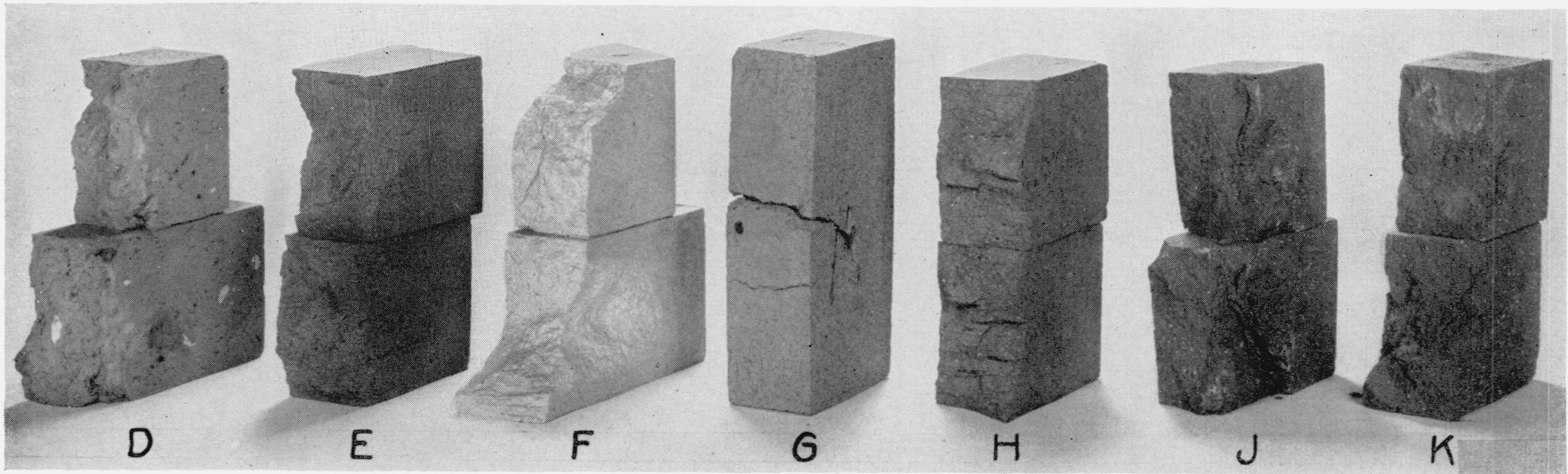

FIGURE 8.-Typical fractures at failure representative of the bricks of the different series. 
The approximate values of the constants representing the curve for $D 9$ are: $a=1.35, b=160$, and $K=105$.

Although the extrapolation of a curve outside of the field covered by the data may not be justifiable, it is often helpful in understanding the significance of certain constants obtained from the data. Asymptote $a$ represents the upper limiting value of $S$, attainable if the brick were to withstand an infinite number of freezing and thawing cycles. Bricks which attained $S$ values greater than unity at failure are seen in the soft-burned bricks of the $G$ series (column 7 , table 11) and in the hard-burned bricks $J 4$ and $J^{7}$ (column 7, table 12). These bricks were distinctly laminated (see fig. 8), the laminations evidently functioning as laminar capillaries, inasmuch as their $V, f, r, N$, and $S_{1}$ values appear to be about normal. The gradual widening of the laminations during successive freezing and thawing evidently was

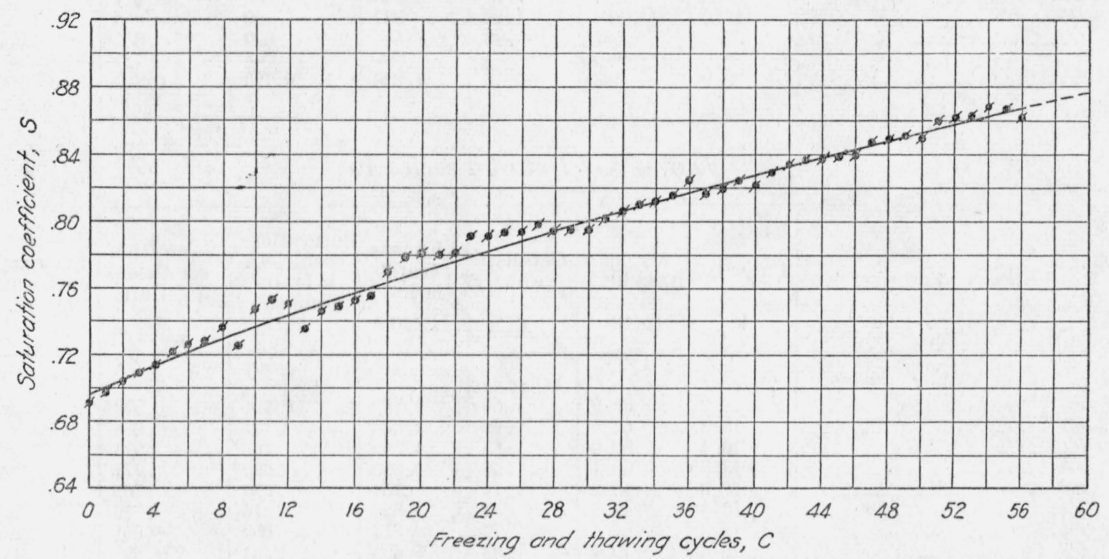

FIGURE 7.-Relation between freezing and thawing cycles and saturation coefficient of brick D9.

responsible for their ability to contain more water at failure than their initial pore volumes.

5. RELATIONS OF POROSITY, PERMEABILITY, EFFECTIVE CAPILLARY RADIUS, NUMBER OF CAPILLARIES, AND SATURATION COEFFICIENT TO THE NUMBER OF FREEZING AND THAWING CYCLES CAUSING FAILURE OF BRICKS

In bricks made of the same clay which are substantially free from defects, it is well known that hardness and mechanical strength increase and porosity decreases with increase in burning temperature, within the temperature ranges of commercially operated kilns. The data on various properties of the several series of bricks presented in tables 8 to 14 suggest some relation within each of the series between porosity and the other properties. There is some evidence that as porosity decreases in each series there is an increase in $r, f$, and $C$ and a decrease in $S_{1}$ and $N$, although in some cases the correlation seems poornotably in the $H, J$, and $K$ series. This is, however, more apparent than real because of insufficient spread of the data for each of the three series from which satisfactory correlations can be made. Although the $C$ values of the $H$ series show considerable spread, there is very 
little difference in the values of $V$ among the different members, indicating that the bricks had received about the same heat treatment during the firing process.

TABLE 8.-Data on series $D$

\begin{tabular}{|c|c|c|c|c|c|c|c|}
\hline Specimen number & $\begin{array}{c}\text { Porosity, } \\
V\end{array}$ & $\begin{array}{c}\text { Air per- } \\
\text { meability, } \\
f \times 10^{5}\end{array}$ & $\begin{array}{c}\text { Capillary } \\
\text { radius, } \\
r\end{array}$ & $\begin{array}{l}\text { Number } \\
\text { of capil- } \\
\text { laries, } \\
N \times 10^{-4}\end{array}$ & $\begin{array}{c}\text { Saturation } \\
\text { coefficient } \\
48 \text { hours' } \\
\text { immersion, } \\
S_{1}\end{array}$ & $\begin{array}{c}\text { Saturation } \\
\text { coefficient } \\
\text { at failure, } \\
S\end{array}$ & $\begin{array}{c}\text { Freezing- } \\
\text { thawing } \\
\text { cycles at } \\
\text { failure, } \\
C\end{array}$ \\
\hline $\begin{array}{l}D 4 \\
D 5 \\
D 10 \\
D 2 \\
D 7 \\
D 3 \\
D 8 \\
D 6 \\
D 9\end{array}$ & $\begin{array}{r}\text { Percent } \\
41.8 \\
41.9 \\
40.7 \\
39.5 \\
36.2 \\
36.5 \\
37.2 \\
37.6 \\
38.4\end{array}$ & $\begin{array}{l}204 \\
214 \\
335 \\
290 \\
453 \\
461 \\
404 \\
366 \\
537\end{array}$ & $\begin{array}{r}\text { Microns } \\
0.85 \\
.87 \\
1.10 \\
1.04 \\
1.36 \\
1.36 \\
1.26 \\
1.20 \\
1.43\end{array}$ & $\begin{array}{r}1,850 \\
1,780 \\
1.070 \\
1,170 \\
628 \\
640 \\
743 \\
837 \\
594\end{array}$ & $\begin{array}{l}0.753 \\
.769 \\
.748 \\
.737 \\
.683 \\
.715 \\
.685 \\
.700 \\
.690\end{array}$ & $\begin{array}{l}0.768 \\
.765 \\
.785 \\
.818 \\
.834 \\
.870 \\
.824 \\
.856 \\
.862\end{array}$ & $\begin{array}{r}2 \\
2 \\
9 \\
27 \\
36 \\
36 \\
37 \\
39 \\
56\end{array}$ \\
\hline A verage. & 38.9 & 363 & 1.16 & 1,030 & 0.720 & 0.820 & 27 \\
\hline
\end{tabular}

TABLE 9.-Data on series $E$

\begin{tabular}{|c|c|c|c|c|c|c|c|}
\hline Specimen number & $\begin{array}{c}\text { Porosity, } \\
V\end{array}$ & $\begin{array}{c}\text { Air per- } \\
\text { meability, } \\
f \times 10^{5}\end{array}$ & $\begin{array}{c}\text { Capillary } \\
\text { radius, } \\
r\end{array}$ & $\begin{array}{l}\text { Number } \\
\text { of capil- } \\
\text { laries, } \\
N \times 10^{-4}\end{array}$ & $\begin{array}{c}\text { Saturation } \\
\text { coefficient } \\
48 \text { hours' } \\
\text { immersion, } \\
S_{1}\end{array}$ & $\begin{array}{c}\text { Saturation } \\
\text { coefficient } \\
\text { at failure, } \\
S\end{array}$ & $\begin{array}{c}\text { Freezing- } \\
\text { thawing } \\
\text { cycles at } \\
\text { failure, } \\
C\end{array}$ \\
\hline $\begin{array}{l}E 8 \\
E 8 \\
E 1 \\
E 5 \\
E 6 \\
E 7 \\
E 44 \\
E 8 \\
E 9 \\
E 10\end{array}$ & $\begin{array}{r}\text { Percent } \\
18.2 \\
19.3 \\
19.4 \\
13.8 \\
12.9 \\
13.4 \\
15.3 \\
10.6 \\
10.6 \\
8.0\end{array}$ & $\begin{array}{l}44.9 \\
61.9 \\
60.6 \\
39.1 \\
48.2 \\
47.6 \\
62.5 \\
49.4 \\
81.7 \\
67.6\end{array}$ & $\begin{array}{r}\text { Microns } \\
0.60 \\
.69 \\
.68 \\
.65 \\
.74 \\
.72 \\
.77 \\
.83 \\
1.07 \\
1.11\end{array}$ & $\begin{array}{r}1,160 \\
1,300 \\
1,340 \\
1,050 \\
751 \\
820 \\
814 \\
495 \\
295 \\
206\end{array}$ & $\begin{array}{l}0.721 \\
.751 \\
.767 \\
.630 \\
.590 \\
.613 \\
.669 \\
.533 \\
.524 \\
.440\end{array}$ & $\begin{array}{r}0.870 \\
.908 \\
.923 \\
.771 \\
.762 \\
.769 \\
.861 \\
.898 \\
.0\end{array}$ & $\begin{array}{r}80 \\
83 \\
86 \\
92 \\
103 \\
105 \\
107 \\
\quad 454 \\
\text { (1) } \\
(1)\end{array}$ \\
\hline Average & 15.4 & 51.8 & .71 & 966 & .659 & .845 & 139 \\
\hline
\end{tabular}

1 Bricks $E 9$ and $E 10$ were still sound after 680 cycles.

2 E9 and E10 excluded.

TABLE 10.-Data on series $F$

\begin{tabular}{|c|c|c|c|c|c|c|c|}
\hline Specimen number & $\begin{array}{c}\text { Porosity, } \\
V\end{array}$ & $\begin{array}{c}\text { Air per- } \\
\text { meability, } \\
f \times 10^{5}\end{array}$ & $\begin{array}{c}\text { Capillary } \\
\text { radius, } \\
r\end{array}$ & $\begin{array}{l}\text { Number } \\
\text { of capil- } \\
\text { laries, } \\
N \times 10^{-4}\end{array}$ & $\begin{array}{c}\text { Saturation } \\
\text { coefficient } \\
48 \text { hours' } \\
\text { immersion, } \\
S_{1}\end{array}$ & $\begin{array}{c}\text { Saturation } \\
\text { coefficient } \\
\text { at failure, } \\
S\end{array}$ & $\begin{array}{c}\text { Freezing- } \\
\text { thawing } \\
\text { cycles at } \\
\text { failure, } \\
C\end{array}$ \\
\hline 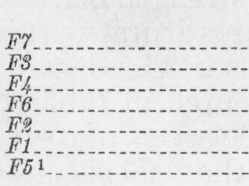 & $\begin{array}{r}\text { Percent } \\
27.0 \\
30.2 \\
31.0 \\
24.6 \\
24.8 \\
19.2 \\
29.6\end{array}$ & $\begin{array}{l}721 \\
186 \\
353 \\
399 \\
461 \\
344 \\
188\end{array}$ & \begin{tabular}{|r|} 
Microns \\
1.98 \\
0.95 \\
1.29 \\
1.54 \\
1.65 \\
1.62 \\
.96
\end{tabular} & $\begin{array}{r}231 \\
1,090 \\
613 \\
333 \\
307 \\
237 \\
1,050\end{array}$ & $\begin{array}{l}0.837 \\
.810 \\
.834 \\
.747 \\
.743 \\
.654 \\
.816\end{array}$ & $\begin{array}{l}0.944 \\
.852 \\
.976 \\
.906 \\
.835 \\
.838\end{array}$ & $\begin{array}{l}15 \\
38 \\
41 \\
51 \\
52 \\
55\end{array}$ \\
\hline A verage ${ }^{2}$. & 26.1 & 411 & 1.50 & 468 & .771 & .892 & 42 \\
\hline
\end{tabular}

1 Used for determination of variation in porosity.

2 F5 excluded. 
TABLe 11.-Data on series $G$ and $H$

\begin{tabular}{|c|c|c|c|c|c|c|c|}
\hline Specimen number & $\begin{array}{c}\text { Porosity, } \\
V\end{array}$ & $\begin{array}{c}\text { Air per- } \\
\text { meability, } \\
f \times 10^{5}\end{array}$ & $\begin{array}{c}\text { Capillary } \\
\text { radius, } \\
r\end{array}$ & $\begin{array}{l}\text { Number } \\
\text { of capil- } \\
\text { laries, } \\
N \times 10^{-4}\end{array}$ & $\begin{array}{c}\text { Saturation } \\
\text { coefficient } \\
48 \text { hours' } \\
\text { immersion, } \\
S_{1}\end{array}$ & $\begin{array}{c}\text { Saturation } \\
\text { coefficient } \\
\text { at failure, } \\
S\end{array}$ & $\begin{array}{l}\text { Freezing- } \\
\text { thawing } \\
\text { cycles at } \\
\text { failure, } \\
\qquad C\end{array}$ \\
\hline $\begin{array}{l}G 9 \\
G 11 \\
G 5 \\
G 2 \\
G S\end{array}$ & $\begin{array}{r}\text { Percent } \\
29.2 \\
26.1 \\
22.5 \\
25.5 \\
24.2\end{array}$ & $\begin{array}{l}550 \\
427 \\
409 \\
970 \\
593\end{array}$ & $\begin{array}{r}\text { Microns } \\
1.66 \\
1.55 \\
1.63 \\
2.36 \\
1.89\end{array}$ & $\begin{array}{l}335 \\
347 \\
268 \\
145 \\
215\end{array}$ & $\begin{array}{l}0.877 \\
.860 \\
.845 \\
.852 \\
.900\end{array}$ & $\begin{array}{l}1.035 \\
1.054 \\
1.045 \\
0.993 \\
1.151\end{array}$ & $\begin{array}{l}45 \\
52 \\
54 \\
54 \\
55\end{array}$ \\
\hline $\begin{array}{l}G 6 \\
G 10 \\
G Y \\
G H \\
G 1 \\
G 81\end{array}$ & $\begin{array}{l}23.5 \\
27.8 \\
28.6 \\
28.7 \\
25.9 \\
20.6\end{array}$ & $\begin{array}{l}495 \\
416 \\
313 \\
346 \\
376 \\
428\end{array}$ & $\begin{array}{l}\text { 1. } 76 \\
1.49 \\
1.27 \\
1.33 \\
1.46 \\
1.75\end{array}$ & $\begin{array}{l}242 \\
395 \\
568 \\
515 \\
386 \\
215\end{array}$ & $\begin{array}{l}.838 \\
.829 \\
.869 \\
.880 \\
.870 \\
.809\end{array}$ & $\begin{array}{l}1.016 \\
1.067 \\
1.005 \\
1.023 \\
1.128\end{array}$ & $\begin{array}{l}57 \\
61 \\
64 \\
64 \\
90 \\
-.\end{array}$ \\
\hline Average 2. & 25.2 & 489 & 1.64 & 341 & .862 & 1.052 & 60 \\
\hline $\begin{array}{l}\mathrm{H}_{5} \\
\mathrm{H}_{4} \\
\mathrm{H} 8 \\
\mathrm{H} 3 \\
\mathrm{H} 6\end{array}$ & $\begin{array}{l}12.3 \\
13.3 \\
13.6 \\
13.7 \\
12.5\end{array}$ & $\begin{array}{l}277 \\
637 \\
813 \\
737 \\
793\end{array}$ & $\begin{array}{l}1.82 \\
2.66 \\
2.97 \\
2.81 \\
3.05\end{array}$ & $\begin{array}{r}117 \\
60 \\
49 \\
55 \\
43\end{array}$ & $\begin{array}{l}.552 \\
.592 \\
.623 \\
.591 \\
.617\end{array}$ & $\begin{array}{l}.899 \\
.910 \\
.921 \\
.896 \\
.794\end{array}$ & $\begin{array}{l}63 \\
80 \\
88 \\
92 \\
93\end{array}$ \\
\hline $\begin{array}{l}H 10 \\
H 1 \\
H 2 \\
H 7 \\
H 9\end{array}$ & $\begin{array}{l}12.4 \\
12.3 \\
11.8 \\
12.2 \\
12.5\end{array}$ & $\begin{array}{l}1,040 \\
1,010 \\
1,460 \\
1,040\end{array}$ & $\begin{array}{l}\text { 3. } 51 \\
\text { 3. } 46 \\
4.19 \\
\text { 3. } 50\end{array}$ & $\begin{array}{c}32 \\
33 \\
-22 \\
35\end{array}$ & $\begin{array}{l}.605 \\
.580 \\
.550 \\
.593 \\
.588\end{array}$ & $\begin{array}{r}.986 \\
.798 \\
.841 \\
.932\end{array}$ & $\begin{array}{l}184 \\
247 \\
310 \\
314\end{array}$ \\
\hline Average ${ }^{2}$... & 12.8 & 846 & 3. 06 & 51 & .594 & .892 & 145 \\
\hline
\end{tabular}

1 Used for determination of variation in porosity.

$2 \mathrm{~GB}, H 2$, and $H 9$ excluded.

TABLE 12.-Data on series $J$ and $K$

\begin{tabular}{|c|c|c|c|c|c|c|c|}
\hline Specimen number & $\begin{array}{c}\text { Porosity, } \\
V\end{array}$ & $\begin{array}{c}\text { Air per- } \\
\text { meability, } \\
f \times 10^{5}\end{array}$ & $\begin{array}{c}\text { Capillary } \\
\text { radius, } \\
r\end{array}$ & $\begin{array}{c}\text { Number } \\
\text { of capil- } \\
\text { laries, } \\
N \times 10^{-1}\end{array}$ & $\begin{array}{c}\text { Saturation } \\
\text { coefficient } \\
48 \text { hours' } \\
\text { immersion, } \\
S_{1}\end{array}$ & $\begin{array}{c}\text { Saturation } \\
\text { coefficient } \\
\text { at failure, } \\
S\end{array}$ & $\begin{array}{l}\text { Freezing- } \\
\text { thawing } \\
\text { cycles at } \\
\text { failure, } \\
C\end{array}$ \\
\hline $\begin{array}{l}J S \\
J 1 \\
J 1 \\
J 6 \\
J 8\end{array}$ & \begin{tabular}{|r|} 
Percent \\
25.6 \\
24.5 \\
26.7 \\
24.9 \\
25.5
\end{tabular} & $\begin{array}{l}2,700 \\
2,510 \\
3,660 \\
2,660 \\
2,780\end{array}$ & $\begin{array}{r}\text { Microns } \\
3.94 \\
3.88 \\
4.49 \\
3.97 \\
4.00\end{array}$ & $\begin{array}{l}52.6 \\
51.8 \\
42.2 \\
50.4 \\
50.6\end{array}$ & $\begin{array}{l}0.804 \\
.760 \\
.775 \\
.764 \\
.772\end{array}$ & $\begin{array}{r}0.945 \\
1.014 \\
.927 \\
.958 \\
.975\end{array}$ & $\begin{array}{l}61 \\
63 \\
63 \\
67 \\
93\end{array}$ \\
\hline $\begin{array}{l}J_{9} \\
J_{4} \\
J_{2} 2 \\
J_{5} \\
J 101\end{array}$ & $\begin{array}{l}25.2 \\
24.7 \\
24.5 \\
25.4 \\
24.8\end{array}$ & $\begin{array}{l}2,820 \\
3,050 \\
2,900 \\
3,320 \\
3,160\end{array}$ & $\begin{array}{l}4.05 \\
4.26 \\
4.17 \\
4.38 \\
4.32\end{array}$ & $\begin{array}{l}48.9 \\
43.3 \\
45.0 \\
42.2 \\
42.2\end{array}$ & $\begin{array}{l}.763 \\
.756 \\
.757 \\
.756 \\
.753\end{array}$ & $\begin{array}{r}.996 \\
1.005 \\
.993 \\
.972 \\
\end{array}$ & $\begin{array}{l}101 \\
107 \\
108 \\
120\end{array}$ \\
\hline Average ${ }^{2}$ & 25.2 & 2,930 & 4.13 & 47.4 & .767 & .976 & 87 \\
\hline $\begin{array}{l}K 5 \\
K 4 \\
K \\
K 8 \\
K 8\end{array}$ & $\begin{array}{l}29.2 \\
28.7 \\
29.6 \\
30.2 \\
30.1\end{array}$ & $\begin{array}{l}1,800 \\
1,960 \\
2,130 \\
2,120 \\
2,020\end{array}$ & $\begin{array}{l}\text { 3. } 00 \\
3.16 \\
3.25 \\
3.21 \\
3.14\end{array}$ & $\begin{array}{r}103.0 \\
91.3 \\
89.3 \\
93.6 \\
97.2\end{array}$ & $\begin{array}{l}.811 \\
.807 \\
.804 \\
.812 \\
.819\end{array}$ & $\begin{array}{l}.943 \\
.979 \\
.946 \\
.932 \\
.945\end{array}$ & $\begin{array}{l}38 \\
38 \\
44 \\
45 \\
47\end{array}$ \\
\hline $\begin{array}{l}K 6 \\
K 9 \\
K 10 \\
K 1\end{array}$ & $\begin{array}{l}28.9 \\
31.0 \\
29.6 \\
30.7 \\
30.0\end{array}$ & $\begin{array}{l}2,140 \\
2,560 \\
2,460 \\
2,590 \\
2,130\end{array}$ & $\begin{array}{l}\text { 3. } 30 \\
3.48 \\
3.50 \\
3.52 \\
3.23\end{array}$ & $\begin{array}{l}84.3 \\
81.4 \\
77.2 \\
78.6 \\
91.8\end{array}$ & $\begin{array}{l}.802 \\
.804 \\
.801 \\
.819 \\
.817\end{array}$ & $\begin{array}{l}.955 \\
.948 \\
.942 \\
.926\end{array}$ & $\begin{array}{l}48 \\
57 \\
58 \\
60\end{array}$ \\
\hline Avera & 29.8 & 2,200 & 3. 28 & 88.4 & .809 & .946 & 48 \\
\hline
\end{tabular}

1 Used for determination of variation in porosity.

2 J10 and $K 3$ excluded. 
TABLE 13.-Effect of higher burning temperaiure of series $H$ over that of series $G$ on the average values of $V, f, r, N, S_{1}$, and $C$

\begin{tabular}{|c|c|c|c|c|c|c|}
\hline \multirow{2}{*}{ Burn } & \multicolumn{3}{|c|}{ Increase } & \multicolumn{3}{|c|}{ Decrease } \\
\hline & $f \times 10^{s}$ & $r$ & $C$ & $V$ & $N \times 10^{-4}$ & $S_{1}$ \\
\hline $\begin{array}{l}\text { Soft, } G \\
\text { Hard, } H\end{array}$ & $\begin{array}{l}489 \\
846\end{array}$ & $\begin{array}{r}\text { Microns } \\
1.64 \\
3.06\end{array}$ & $\begin{array}{r}60 \\
145\end{array}$ & $\begin{array}{l}26.2 \\
12.8\end{array}$ & $\begin{array}{r}341 \\
51\end{array}$ & $\begin{array}{r}0.862 \\
.594\end{array}$ \\
\hline Difference. & 357 & 1.42 & 85 & 13.4 & 290 & 0.268 \\
\hline Difference (\%) & 73.0 & 86.6 & 141.7 & 51.2 & 85.0 & 31.1 \\
\hline
\end{tabular}

TABLE 14.-Effect of higher burning temperature of series $J$ over that of series $K$ on the average values of $V, f, r, N, S_{1}$, and $C$

\begin{tabular}{|c|c|c|c|c|c|c|}
\hline \multirow{2}{*}{ Burn } & \multicolumn{3}{|c|}{ Increase } & \multicolumn{3}{|c|}{ Decrease } \\
\hline & $f \times 10^{5}$ & $r$ & $C$ & V & $N \times 10^{-4}$ & $S_{i}$ \\
\hline $\begin{array}{l}\text { Medium, } K \\
\text { Hard, } J\end{array}$ & $\begin{array}{l}2,200 \\
2,930\end{array}$ & $\begin{array}{r}\text { Microns } \\
3.28 \\
4.13\end{array}$ & $\begin{array}{l}48 \\
87\end{array}$ & $\begin{array}{l}29.8 \\
25.2\end{array}$ & $\begin{array}{l}88.4 \\
47.4\end{array}$ & $\begin{array}{r}0.809 \\
.767\end{array}$ \\
\hline Difference........... & 730 & 0.85 & 39 & 4.6 & 41.0 & 0.042 \\
\hline Difference $(\%)$ & 33.2 & 25.9 & 81.2 & 15.3 & 46.4 & 5.2 \\
\hline
\end{tabular}

The bricks of both the $J$ and $K$ series were made of the same kind of clay by the dry-press process and fired in the same kiln. The harder burned bricks of series $J$ were selected from near the top courses of the setting of a down-draft kiln in the higher temperature zone, and the softer burned ones of series $K$ from near the bottom of the setting in the lower temperature zone.

Bricks of the other five series were selected from lots such as are delivered to the builder. The bricks of each series may have come from different locations in the kiln and, therefore they would have been subjected to different temperatures. Therefore, the data would show greater spread than is shown by either the $H, J$, or $K$ series.

Bricks of the $G$ and $H$ series were made of shale by the stiff-mud process at the same plant. They had been graded for the market, the harder bricks of the $H$ series coming from the top portion of the kiln and the softer ones of series $G$ from the bottom.

Comparing average values of series $G$ with those of series $H$ (table 13) and those of series $K$ with those of series $J$ (table 14), it is seen that harder burning has resulted in material reductions in the porosity, number of capillaries, and saturation coefficient, and increases in the air permeability, capillary radius, and cycles of freezing and thawing to cause failure.

The above findings on porosity, air permeability, effective capillary radius, and number of capillaries are in accord with those given in the reports of the following investigators.

Watkins and Butterworth ${ }^{18}$ determined the total porosity and the microporosity of a clay fired at four different temperatures from $750^{\circ}$ to $1,105^{\circ} \mathrm{C}$ and report the following results with increase in the firing temperature: "The microporosity decreases much more rapidly than

18 C. M. Watkins andiB. Butterworth, The absorption of water by clay building brick and some related prop erties, Trans._Eng.'Ceram. Soc. 33, 473 (1933-4). 
the total porosity at high temperatures. In other words, although the total pore volume is decreasing, the size of the individual pores tends to increase."

Clews and Green ${ }^{19}$ in a report on the determination of the air permeability of a number of fire clays fired at eight different temperatures from $200^{\circ}$ to $1,400^{\circ} \mathrm{C}$, show that " . . . . . . the firing procedure involves a continuous increase in pore size, with corresponding but not necessarily proportional decrease in the number of the pores up to the temperature approaching the finishing." Table I of their report shows that the permeability to air increases with increase in firing temperature from $200^{\circ}$ to $1,250^{\circ} \mathrm{C}$ for four groups of fire clays. In one case the increase in the permeability ranged from 0.00097 to 0.0460 .

The decrease in porosity and number of capillaries indicates that some pores were filled or sealed and thus were inactive regarding permeability and absorption. The increase in permeability, together with the decrease in number of pores, indicates that the pores eliminated were mostly the smaller pores, or micropores, which were the interstitial cavities formed by the microparticles. These particles are composed mainly of mixtures of minute mineral fragments. From such particles glasses form at lower temperatures than from coarser ones and the reaction proceeds more rapidly for the finer particles; hence the number of small pores is materially reduced.

The increase in permeability with increase in burning temperature, in spite of a decrease in the number of pores, may be due to enlargement of the connecting pore openings because of partial fusion and to a receding of the angular edges of the openings between adjacent pores. The effective capillary radius, $r$, is increased and the number of capillaries, $N$, decreased, because $f$ increases and $V$ decreases with increase in burning temperature. (See eq 6 and 7).

The bricks in each series as selected appear to be representative of the range in variation of grades as marketed. Among such bricks there is not only insufficient spread of the data, but uncontrollable factors also, such as laminations and variable porosity, which are contributing factors tending to lower the $C$ values. These are some of the handicaps encountered when dealing with bricks of commercial grade. In the majority of cases, however, the general trend of the data given in tables 8 to 14 , inclusive, indicates that the number of cycles of freezing and thawing at failure of bricks increases when the permeability and mean effective capillary radius increase and when the porosity, number of capillaries, and saturation coefficient decrease.

\section{SUMMARY}

1. Variation in porosity of individual bricks is one measure of their lack of uniform structure and may be a contributing factor affecting their resistance to frost action.

2. There is no definite correlation as to location of lowest, medium, and highest porosities of the sections among the bricks tested. The spread of the differences between maximum and minimum percentage porosities of the different sections of the individual bricks ranged from 11.6 to 48.42 percent.

\footnotetext{
19 F. H. Clews and A. T. Green, The permeability of refractory materials to gases. Part IV. The influence of the firing process on the permeability to air of fire-clay materials, Trans. Eng. Ceram. Soc., 33, 485 (1933-4). $269047-41-8$
} 
3 . When the air permeabilities of two bricks are $f_{1}$ and $f_{2}$, respectively, and their respective thicknesses, $T_{1}$ and $T_{2}$, then the air transmission, or air conductance, $F$, of the two bricks in series may be calculated by the equation

$$
F=\frac{f_{1} f_{2}}{f_{1} T_{2}+f_{2} T_{1}} .
$$

The differences between the calculated and experimental values for $F$ were so small as to be negligible.

4. The average values of the data for the bricks of series $G$ and $H$ and also series $K$ and $J$ indicate that the mean effective capillary radius, the permeability, and number of cycles of freezing and thawing at failure of the bricks increase and the number of capillaries, pore volume, and initial saturation coefficient decrease, as the burning temperature of the bricks is increased.

5. Decrease in pore volume and number of pores as the burning temperature is increased indicates that some of the pores have become filled or sealed and, therefore, inactive regarding permeability and absorption. Increase in mean effective capillary radius and permeability, accompanied by a decrease in the number of pores, indicates that the pores rendered inactive were chiefly the smaller ones originally occurring as microcavities formed by the microparticles. Increase in permeability with the firing temperature must, therefore, result from an enlargement of the larger connecting pore openings, which may be due to partial fusion and receding of the angular edges of the openings between adjacent pores.

6. The air permeabilities were constant with respect to time of flow whereas the water permeabilities varied, increasing for those bricks whose mean effective capillary radii were less than 2 microns and decreasing for those whose radii were greater than 2 microns.

7. The saturation coefficients increased with increase in the number of freezing and thawing cycles, and the graph representing the plot of the two variables can be represented fairly well by an equation of a hyperbola of the form

$$
S=a-\frac{K}{b+C},
$$

where $C$ is the cycle number of freezing and thawing, $S$ the corresponding saturation coefficient, and $a, b$, and $K$ are constants for a definite brick but different for different bricks. The constant $a$ indicates that there is an upper limiting value of $S$ for a brick, under the assumption that the brick would withstand (theoretically) an infinite number of freezing and thawing cycles.

8. Repeated freezing, and thawing by immersion, of some bricks may increase their saturation coefficients to values greater than unity, thus indicating that they contain larger volumes of water than their original pore volumes.

9. In bricks substantially free from defects, the general trend of the data indicates that the number of cycles of freezing and thawing to cause failure increases when the air permeability and mean effective capillary radius increase, and when the saturation coefficient, porosity and number of capillaries decrease.

Washington, September 13, 1940. 